\title{
Back to the future: restricted protein intake for conservative management of CKD, triple goals of renoprotection, uremia mitigation, and nutritional health
}

\author{
Csaba P. Kovesdy ${ }^{1,2} \cdot$ Kamyar Kalantar-Zadeh ${ }^{3}$
}

Received: 20 December 2015 / Accepted: 18 January 2016 / Published online: 17 February 2016

(C) Springer Science+Business Media Dordrecht 2016

\begin{abstract}
Lowering dietary protein intake (DPI) to approximately $0.6-0.8 \mathrm{~g} / \mathrm{kgBW} /$ day may be renoprotective through various mechanisms, and it has been recommended in patients with non-dialysis-dependent chronic kidney disease (NDD-CKD) as a means to also control various metabolic consequences of advanced CKD, such as uremic symptoms, hyperparathyroidism, hypertension, hyperkalemia, and hyperphosphatemia. A meta-analysis in this issue of the Journal suggests that low-protein diet is effective and safe when used to retard progression of CKD and alleviate uremic complications. A potential deleterious consequence of lowering DPI in this population is the development or worsening of protein-energy wasting (PEW), which can contribute to poor clinical outcomes such as higher mortality and morbidity. There is currently insufficient high-level evidence to determine the ideal level of DPI in patients with NDD-CKD with high risk of PEW. For the time being we recommend a DPI of $0.6-0.8 \mathrm{~g} / \mathrm{kgBW} /$ day, and increasing this as needed on an individual basis in patients with PEW. Further examination of this dilemma in randomized controlled clinical trials will be necessary.
\end{abstract}

Kamyar Kalantar-Zadeh

kamkal@ucla.edu

Csaba P. Kovesdy

ckovesdy@uthsc.edu

1 Division of Nephrology, University of Tennessee Health Science Center, 956 Court Avenue, Memphis, TN 38163 , USA

2 Nephrology Section, Memphis Veterans Affairs Medical Center, Memphis, TN, USA

3 Harold Simmons Center for Kidney Disease Research and Epidemiology, University of California Irvine Medical Center, Orange, CA, USA
Keywords Protein-energy wasting · Chronic kidney disease $\cdot$ Nutritional supplements $\cdot$ Low-protein diets

\section{Introduction}

Nutritional management in NDD-CKD is implemented with the aim of achieving triple goals, namely the need to reconcile treatment and prevention of protein-energy wasting (PEW) with the amelioration of progression of CKD and also to mitigate uremia and its related morbidities. The cornerstone of nutritional management in NDD-CKD is manipulation of the amount of dietary protein intake (DPI). The effect of various levels of DPI on kidney function and progression of CKD has been studied in multiple clinical trials, but not in the context of coexisting PEW, while the fear of PEW is often mentioned as a reason to avoid restricted diet [1].

In this commentary article for the new meta-analyses by Jiang et al. [2] on the effect of restricted protein diet supplemented with keto-analogs, we provide a summary of the nutritional needs of patients with NDD-CKD, the pathophysiology of PEW in NDD-CKD, the effects of DPI on kidney function and CKD progression, and of the nutritional treatment strategies toward optimizing outcomes in NDD-CKD.

\section{Dietary protein intake requirements in CKD}

Adult CKD patients without an acute illness have dietary protein requirements similar to normal healthy individuals, which is about $0.6 \mathrm{~g} / \mathrm{kgBW} /$ day. Current recommendations from FAO/WHO and the Food and Nutrition Board of the National Academy of Sciences are $30 \%$ above this level 


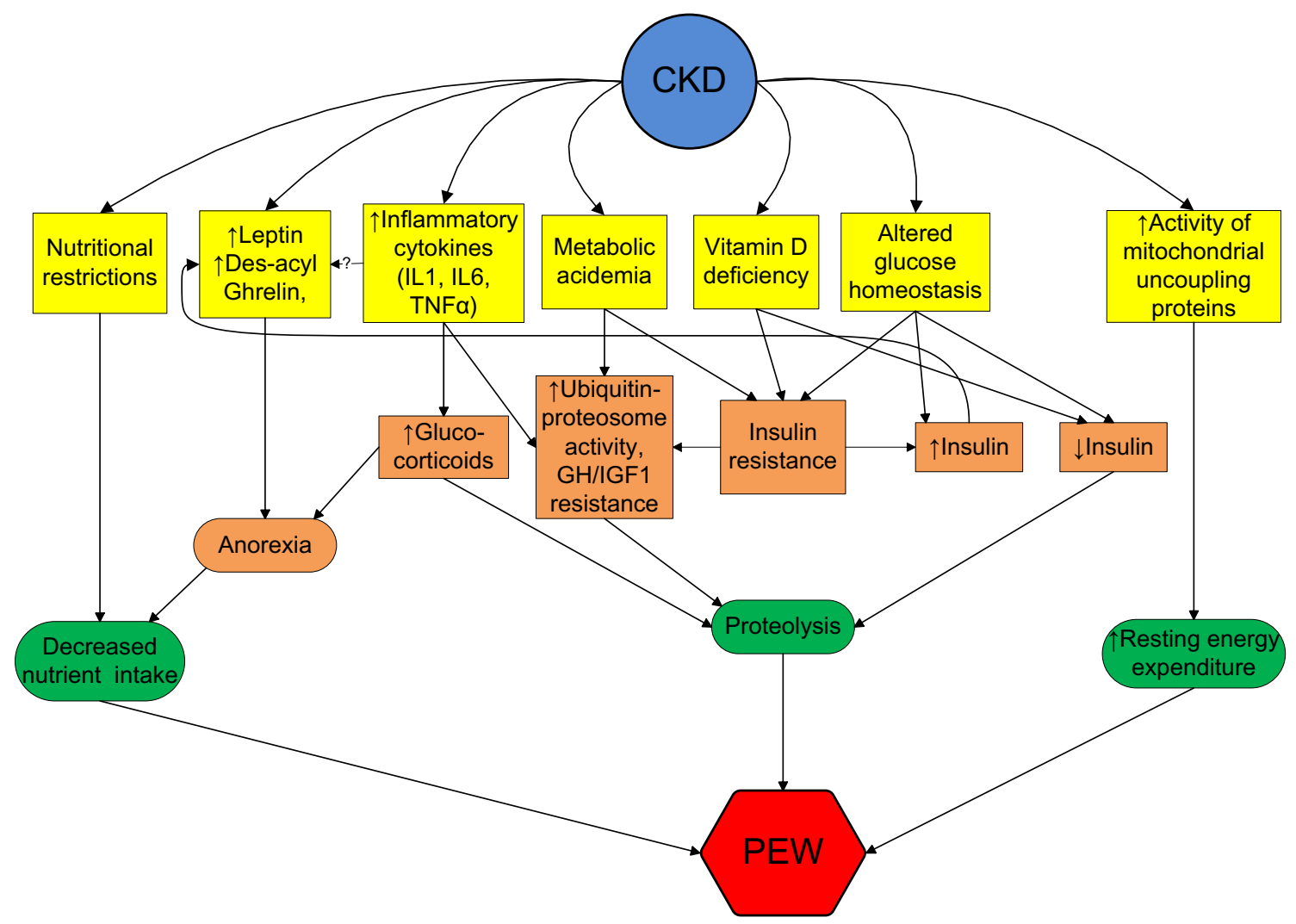

Fig. 1 Mechanisms leading to protein-energy wasting in patients with chronic kidney disease. Adapted from Kovesdy et al. Am J Clin Nutr 2013;97:1163-77

to offer a safety margin, i.e., a DPI of $0.8 \mathrm{~g} / \mathrm{kgBW} /$ day in normal adults [3]. Indeed, $0.6-0.8 \mathrm{~g} / \mathrm{kgBW} /$ day is identical to what is referred to as "low-protein diet" recommended in patients with NDD-CKD [4]. This apparent misnomer is due to the fact that the average DPI in the general Western population is significantly higher (e.g., approximately $1.0-1.3 \mathrm{~g} / \mathrm{kgBW} /$ day in US adults [5]). The actual recommended DPI in NDD-CKD might vary depending on individual patient characteristics: higher DPI may be required in elderly patients [6], and those who are acutely ill, catabolic, or suffering from PEW [6-8]. While there is in general agreement that patients with PEW and NDD-CKD should be allowed a higher DPI temporarily, there is no clear understanding of what the exact amount of this should be. A recent consensus statement from the International Society of Renal Nutrition and Metabolism (ISRNM) suggests a DPI of $1 \mathrm{~g} / \mathrm{kgBW} /$ day in such patients [7], while others suggest to maintain LPD of $0.6-0.8$ but to supplement it with keto-analogs or essential amino acids [9]. In addition to adequate DPI, there should also be adequate dietary energy provision of $30-35 \mathrm{Cal} / \mathrm{kg} / \mathrm{BW} /$ day.

An oft-cited concern of low-protein diet interventions is the risk of PEW. The mechanisms underlying the development of PEW in NDD-CKD are complex (Fig. 1) with both anorexia and enhanced protein catabolism playing distinct roles. The pathophysiology of PEW in CKD involves a combination of factors such as increases in anorexigenic hormones, activation of pro-inflammatory cytokines, enhanced activity of catabolic hormones, decreased levels or resistance to anabolic hormones, metabolic acidemia, vitamin D deficiency and abnormal glucose and insulin homeostasis [10]. However, it has never been shown whether prescribed LPD can cause PEW. Indeed in the Modification of Diet in Renal Disease (MDRD) study, only two out of several hundred participants discontinued the LPD because of signs of PEW [11, 12].

\section{Low-protein diet in CKD}

Excess DPI, along with higher intake of sodium, phosphorus, and potassium, can lead to undesirable effects in NDD-CKD, such as the uremic syndrome, oxidative stress, altered endothelial function, reduced nitric oxide production, metabolic acidosis, and insulin resistance [13]. Reducing DPI has been advocated to alleviate these effects and can result in control of hyperparathyroidism, acidosis, hyperphosphatemia and hyperkalemia, reduction in 
proteinuria, and slower loss of kidney function [14]. The MDRD study was a large randomized controlled clinical trial that examined the effects of various levels of lowprotein diet with and without keto-analog supplementation on the progression of CKD and some additional outcomes such as blood pressure. The main findings of the MDRD study was reported negative [11], but this may have been the consequence of an abrupt drop in GFR from initiation of protein restriction in the first several weeks, and when accounting for this effect in a secondary analysis, patients who were prescribed protein restriction experienced significantly improved outcomes [12].

Before and after the MDRD study, several smaller clinical trials were conducted to examine renoprotection with various types of low DPI interventions. Some meta-analyses of such clinical trials confirmed a benefit toward renoprotection, and also benefits toward controlling hyperparathyroidism, hypertension, acidosis and hyperphosphatemia, while avoiding deleterious effects such as PEW $[2,15,16]$ including by Jiang et al. in this issue of the Journal (see below). However, a meta-analysis of trials performed in diabetic nephropathy patients could not find a significant benefit from low-protein diet [17]. The reason for this may be the different pathophysiology of diabetic nephropathy, or the higher proportion of renin-angiotensin-aldosterone inhibitor use in this population, which could offset the glomerular effects of high protein intake. Due to such inconsistencies and the overall weaker level of evidence, prevailing guidelines have put forth DPI reduction to $0.6-0.8 \mathrm{~g} / \mathrm{kg} /$ day as a "weak recommendation," and not primarily for renoprotection, but for the other numerous benefits associated with it, e.g., reduction in uremic symptoms and better metabolic control [8].

In this issue of the Journal, Jiang et al. have presented their most recent meta-analysis of nine selected studies including seven randomized control trials, one crossover trial and one non-randomized concurrent control trial and examined collective changes in eGFR, nutritional markers (BMI, lean body mass and mid-arm muscle circumference), and serum levels of relevant measures (urea, creatinine, albumin, PTH, minerals, and lipids) and reported that compared with normal protein diet, the low-protein diet (LPD) or very low protein diet supplemented with keto-analogs (sVLPD) slowed effectively the drop in eGFR over time $(p<0.001)$. They also reported some favorable effects on correction of secondary hyperparathyroidism, hypertension, and hyperphosphatemia. While they reported no differences in serum creatinine, albumin, lipids, or anemia or nutritional markers, serum urea was $14.25 \mathrm{mg} / \mathrm{dl}$ lower in the LPD group (95\% CI $28.79-0.30 \mathrm{mg} / \mathrm{dL}, p=0.05$ ). Hence, this meta-analysis adds to the pool of evidence that LPD is effective in the management of CKD without compromising safety and without causing PEW. Nevertheless, a relevant question for this day and age of conservative management of advanced CKD has remained open as to whether LPD can control uremia to allow late start or complete postponing of dialysis transition. Given the borderline significant drop in serum urea in the LPD group, we believe that this is implied by this meta-analysis.

\section{Risks of DPI modification in CKD}

Notwithstanding the putative benefits of low-protein diet on progression of CKD and on uremic signs and symptoms, an overzealous and dogmatic approach to protein restriction could be deleterious, considering that the nutritional needs of some individuals may occasionally differ from those established in guidelines. One potential cause of PEW is decreased DPI $[18,19]$; adequate DPI is essential toward maintaining one's health and well-being, and therapeutic restriction of DPI to pre-defined targets and without considering individual nutritional needs runs the risk of unintended adverse consequences. There was no increase in mortality or hospitalization rates in MDRD, and serum levels of albumin were stable throughout the duration of the trial. However, other nutritional parameters such as body weight and muscle mass declined in patients who received supplemented very low protein intake [11, 20]. Furthermore, there was higher mortality in patients randomized to the supplemented very low protein diet (targeting $0.3 \mathrm{~g} /$ $\mathrm{kgBW} /$ day) in a post hoc analysis [21].

As mentioned above, certain groups of patients such as the elderly, the acutely ill, or those with established PEW [6-8] may require a DPI that is temporarily higher than the generally recommended low-protein diet. It is important that such manipulations in DPI are achieved under close scrutiny to avoid deleterious consequences of increased protein intake, such as increased uremic symptoms or worsening of CKD [22-24]. This can be achieved through dietary counseling and periodic monitoring; when counseling is unsuccessful, supplementation with formulations containing high biological value proteins or their equivalents provides additional therapeutic options, with the additional benefit of easier control over the biologic value of ingested proteins, the amount of energy intake, and restriction of sodium, potassium, and phosphorus intake. Protein, amino acid, or keto-acid supplementation is effective in improving PEW irrespective of its etiology [25], but it remains unclear whether or not such supplementations can also lead to better clinical outcomes, such as improved survival or lower CKD progression rate. Dialysis patients receiving oral and parenteral nutritional supplements have experienced greater survival in observational studies or secondary analyses of clinical trials [26-28], but these findings have yet to be 
replicated in prospective randomized controlled trials, and in particularly in NDD-CKD.

Patients with PEW who develop adverse effects from higher DPI in spite of efforts to prevent this could represent a difficult therapeutic dilemma. Such patients may require alternative measures, such as correction of acidemia [29-33], prevention of the absorption of toxic compounds derived from protein metabolism (such as phosphorus, potassium, indoles, phenols, cresol, urea, guanidines and middle molecules) $[34,35]$, or initiation of renal replacement therapy.

\section{Conclusions}

Lowering DPI to approximately $0.6-0.8 \mathrm{~g} / \mathrm{kgBW} /$ day in patients with NDD-CKD is considered renoprotective, with recent evidence suggesting that its implementation in stable, non-catabolic patients can be effective and safe [2]. Low protein intake may mitigate uremic symptoms and allow conservative management of advanced CKD without the need to transition to dialysis. However, many NDD-CKD patients suffer from PEW, and its treatment requires (among others) the provision of proper amounts of DPI [25]. Since uncontrolled high protein intake can have multiple deleterious consequences, dietary interventions for PEW must balance adequate DPI with avoiding adverse effects of high protein intake, such as worsened progression of CKD. This therapeutic dilemma can be resolved with careful attention to not only the quantity, but also the quality of ingested proteins, the provision of proper energy intake, the use of alternative renoprotective strategies such as inhibitors of the renin-angiotensin-aldosterone system and correction of metabolic acidemia, supplementing protein in the diet with essential nutrients or using supplements that are specifically designed for CKD patients [36], and by individualizing the amount of protein intake according to specific patient characteristics such as age or individual response to dietary interventions. Patients with PEW may temporarily require higher amounts of DPI in the range of $1 \mathrm{~g} / \mathrm{kg} /$ day. The efficacy and safety of these strategies will need to be tested in clinical trials.

Acknowledgments Drs. Kovesdy and Kalantar-Zadeh are employees of the US Department of Veterans affairs. Opinions expressed in this paper are those of the authors and do not necessarily represent the opinion of the US Department of Veterans Affairs.

\section{Compliance with ethical standards}

Conflict of interest Dr. Kovesdy has received honoraria from Abbott Nutrition, Relypsa, Sanofi-Aventis and ZS Pharma. Dr. KalantarZadeh has received honoraria from Abbott, Abbvie, Alexion, Amgen, AstraZeneca, Aveo, Chugai, DaVita, Fresenius, Genentech, Haymar- ket Media, Hospira, Kabi, Keryx, Novartis, Pfizer, Relypsa, Resverlogix, Sandoz, Sanofi, Shire, Vifor, UpToDate, and ZS Pharma.

\section{References}

1. Kalantar-Zadeh K, Tortorici AR, Chen JL et al (2015) Dietary restrictions in dialysis patients: Is there anything left to eat? Semin Dial 28:159-168

2. Jiang Z, Zhang X, Yang L, Li Z, Qin W (2015) Effect of restricted protein diet supplemented with Keto analogues in chronic kidney disease: a systematic review and meta-analysis. Int Urol Nephrol

3. Panel on Macronutrients ARot, Subcommittees on Upper Reference Levels of Nutrients and Interpretation and Uses of Dietary Reference Intakes, Standing Committee on the Scientific Evaluation of Dietary Reference Intakes (2005) Dietary reference intakes for energy, carbohydrate, fiber, fat, fatty acids, cholesterol, protein, and amino acids (Macronutrients). The National Academies Press, Washington

4. National Kidney Foundation (2000) K/DOQI clinical practice guidelines for nutrition in chronic renal failure. Am J Kidney Dis 35:s1-s140

5. Fulgoni VL III (2008) Current protein intake in America: analysis of the National Health and Nutrition Examination Survey, 2003-2004. Am J Clin Nutr 87:1554S-1557S

6. Deutz NE, Bauer JM, Barazzoni R et al (2014) Protein intake and exercise for optimal muscle function with aging: recommendations from the ESPEN Expert Group. Clin Nutr 33:929-936

7. Ikizler TA, Cano NJ, Franch H et al (2013) Prevention and treatment of protein energy wasting in chronic kidney disease patients: a consensus statement by the International Society of Renal Nutrition and Metabolism. Kidney Int 84:1096-1107

8. KDIGO (2012) clinical practice guideline for the evaluation and management of chronic kidney disease. Kidney Int Suppl 3(1-150):2013

9. Shah AP, Kalantar-Zadeh K, Kopple JD (2015) Is there a role for ketoacid supplements in the management of CKD? Am J Kidney Dis 65:659-673

10. Kovesdy CP, Kopple JD, Kalantar-Zadeh K (2013) Management of protein-energy wasting in non-dialysis-dependent chronic kidney disease: reconciling low protein intake with nutritional therapy. Am J Clin Nutr 97:1163-1177

11. Klahr S, Levey AS, Beck GJ et al (1994) The effects of dietary protein restriction and blood-pressure control on the progression of chronic renal disease modification of diet in Renal Disease Study Group. N Engl J Med 330:877-884

12. Levey AS, Greene T, Beck GJ et al (1999) Dietary protein restriction and the progression of chronic renal disease: what have all of the results of the MDRD study shown? Modification of diet in Renal Disease Study group. J Am Soc Nephrol 10:2426-2439

13. D'Apolito M, Du X, Zong H et al (2010) Urea-induced ROS generation causes insulin resistance in mice with chronic renal failure. J Clin Invest 120:203-213

14. Chauveau P, Combe C, Rigalleau V, Vendrely B, Aparicio M (2007) Restricted protein diet is associated with decrease in proteinuria: consequences on the progression of renal failure. J Ren Nutr 17:250-257

15. Kasiske BL, Lakatua JD, Ma JZ, Louis TA (1998) A meta-analysis of the effects of dietary protein restriction on the rate of decline in renal function. Am J Kidney Dis 31:954-961

16. Fouque D, Laville M (2009) Low protein diets for chronic kidney disease in non diabetic adults. Cochrane Database Syst Rev CD001892 
17. Robertson L, Waugh N, Robertson A (2007) Protein restriction for diabetic renal disease. Cochrane Database Syst Rev CD002181

18. Bergstrom J (1995) Why are dialysis patients malnourished? Am J Kidney Dis 26:229-241

19. Ikizler TA, Greene JH, Wingard RL, Parker RA, Hakim RM (1995) Spontaneous dietary protein intake during progression of chronic renal failure. J Am Soc Nephrol 6:1386-1391

20. Kopple JD, Levey AS, Greene T et al (1997) Effect of dietary protein restriction on nutritional status in the modification of Diet in Renal Disease Study. Kidney Int 52:778-791

21. Menon V, Kopple JD, Wang X et al (2009) Effect of a very lowprotein diet on outcomes: long-term follow-up of the Modification of Diet in Renal Disease (MDRD) Study. Am J Kidney Dis 53:208-217

22. King AJ, Levey AS (1993) Dietary protein and renal function. J Am Soc Nephrol 3:1723-1737

23. Wasserstein AG (1993) Changing patterns of medical practice: protein restriction for chronic renal failure. Ann Intern Med 119:79-85

24. de Jong PE, Anderson S (1993) de ZD: glomerular preload and afterload reduction as a tool to lower urinary protein leakage: will such treatments also help to improve renal function outcome? J Am Soc Nephrol 3:1333-1341

25. Kalantar-Zadeh K, Cano NJ, Budde K, Chazot C, Kovesdy CP, Mak RH, Mehrotra R, Raj DS, Sehgal AR, Stenvinkel P, Ikizler TA (2011) Diets and enteral supplements for improving outcomes in chronic kidney disease. Nat Rev Nephrol 7(7):369384. doi:10.1038/nrneph.2011.60

26. Lacson E Jr, Wang W, Zebrowski B, Wingard R, Hakim RM (2012) Outcomes associated with intradialytic oral nutritional supplements in patients undergoing maintenance hemodialysis: a quality improvement report. Am J Kidney Dis 60:591-600

27. Chertow GM, Ling J, Lew NL, Lazarus JM, Lowrie EG (1994) The association of intradialytic parenteral nutrition administration with survival in hemodialysis patients. Am J Kidney Dis 24:912-920
28. Cano NJ, Fouque D, Roth $\mathrm{H}$ et al (2007) Intradialytic parenteral nutrition does not improve survival in malnourished hemodialysis patients: a 2-year multicenter, prospective, randomized study. J Am Soc Nephrol 18:2583-2591

29. Graham KA, Reaich D, Channon SM et al (1996) Correction of acidosis in CAPD decreases whole body protein degradation. Kidney Int 49:1396-1400

30. Graham KA, Reaich D, Channon SM, Downie S, Goodship TH (1997) Correction of acidosis in hemodialysis decreases wholebody protein degradation. J Am Soc Nephrol 8:632-637

31. Lofberg E, Wernerman J, Anderstam B, Bergstrom J (1997) Correction of acidosis in dialysis patients increases branched-chain and total essential amino acid levels in muscle. Clin Nephrol 48:230-237

32. Verove C, Maisonneuve N, El AA, Boldron A, Azar R (2002) Effect of the correction of metabolic acidosis on nutritional status in elderly patients with chronic renal failure. J Ren Nutr $12: 224-228$

33. Movilli E, Zani R, Carli O et al (1998) Correction of metabolic acidosis increases serum albumin concentrations and decreases kinetically evaluated protein intake in haemodialysis patients: a prospective study. Nephrol Dial Transplant 13:1719-1722

34. Niwa T, Nomura T, Sugiyama S et al (1997) The protein metabolite hypothesis, a model for the progression of renal failure: an oral adsorbent lowers indoxyl sulfate levels in undialyzed uremic patients. Kidney Int Suppl 62:S23-S28

35. Schulman G, Agarwal R, Acharya $M$ et al (2006) A multicenter, randomized, double-blind, placebo-controlled, dose-ranging study of AST-120 (Kremezin) in patients with moderate to severe CKD. Am J Kidney Dis 47:565-577

36. Montes-Delgado R, Guerrero Riscos MA, Garcia-Luna PP et al (1998) Treatment with low-protein diet and caloric supplements in patients with chronic kidney failure in predialysis. Comparative study. Rev Clin Esp 198:580-586 